\title{
Especialidades Médicas - Urologia
}

\author{
José Cury
}

\section{Interesse pela especialidade}

A especialidade relacionada ao aparelho urinário já estava incutida na minha mente, dado que meu pai faleceu de problema renal, devido a uma hipertensão arterial.

\section{Medos e descrição da especialidade}

Em se tratando de medicina, deve-se sempre ter uma premonição, já que se trata de uma carreira de dedicação integral: o paciente se torna o alvo de todo o seu direcionamento. A urologia é uma especialidade de horizontes muito amplos, ou seja, o profissional atende a uma gama de pacientes que têm: doenças intra-uterinas, anomalias renais de bexiga; crianças com infecção urinária, tumores de rim, crianças masculinas cujos testículos não desceram para a bolsa testicular; pacientes adolescentes com problemas genitais, no comprimento do pênis, no tamanho dos testículos; pacientes no grupo dos 15 aos 35 anos com a predominância de tumores de testículo, jovens com litíase urinária ("pedra no rim"), pessoas com infertilidade; mulheres com cistites de repetição, após $1^{\circ}$ relacionamento sexual; na maturidade há um grande contingente de homens com câncer de próstata e mulheres com incontinência urinária, que tiveram partos, homens urinando sangue, com tumor de via excretora; na idade mais avançada, há homens e mulheres utilizando fraldas, devido à incontinência urinária (bexiga hiperativa e hiperreflexa), deficiência androgênica do homem idoso (queda da testosterona, que causa disfunção erétil, problemas de osteoporose e perda de massa muscular, levando ao hipogonadismo).
Trata-se, portanto, de uma especialidade ampla, geral e restrita, com horizontes inimagináveis. Para se ter uma idéia, a urologia é a primeira especialidade em que houve o sucesso de transplantes: o renal. E o Brasil é um dos países mais avançados nessa área de transplantes, levando em conta as operações feitas em hospitais como o Hospital das Clínicas e o Hospital do Rim e Hipertensão.

\section{A situação da urologia no Instituto Central do Hospital das Clínicas}

A urologia caminha seguindo os passos do Professor Doutor Miguel Srougi. Há 7 anos, ele montou um serviço de alto padrão (CAPES 6) com Homero Bruschini. Tratava-se de um trabalho acima de qualquer perspectiva existente nessa disciplina. Desse modo, com uma graduação forte, a área de urologia apresenta um índice de aprovação variando de 90 a $95 \%$ e é caracterizada como a melhor especialidade do Curso de Clínica Cirúrgica da Faculdade de Medicina da Universidade de São Paulo (FMUSP).

Aqui há a Liga Acadêmica Urológica (LAU), altamente atuante, envolvendo alunos do $4^{\circ}$ ano da Faculdade de Medicina. Ocorreu no próprio andar da urologia uma reforma de oito milhões de reais, financiada integralmente por Aloysio de Andrade Faria, dono do Banco Real. Essa reforma consistiu de duas salas cirúrgicas de última geração, inexistentes até nos melhores hospitais de São Paulo (como Sírio Libanês e Albert Einstein). As salas foram inauguradas em outubro de 2011 e não entraram em funcionamento até hoje, devido à falta de material

Assistente Doutor Coordenador da Graduação Médica e Chefe do Grupo de Medicina Sexual da Divisão de Urologia do HC-FMUSP. 
humano não-medico, ou seja, enfermeiros, auxiliares de enfermagem, instrumentadores e técnicos de radiologia, que o hospital não conseguiu prover ainda.

É realmente triste uma unidade desse porte não estar em funcionamento: a conseqüência disso é o residente, que deixa de praticar o manuseio de instrumentos de alta tecnologia. Em breve (final de maio, aproximadamente), terá início uma outra reforma do outro lado da enfermaria. Essa custará 3 milhões de reais.

O que é a LAU? A Liga Acadêmica Urológica (LAU) é uma sociedade sem fins lucrativos, fundada em agosto de 2005 e constituída por estudantes da Faculdade de Medicina da Universidade de São Paulo (FMUSP) que tem maior interesse na área de urologia. Os objetivos da LAU são:

$\checkmark$ aprimorar o conhecimento científico área de urologia;

$\checkmark$ aperfeiçoar a relação médico-paciente através de atendimentos ambulatoriais;

$\checkmark$ promover integração entre o aluno de graduação e os professores da disciplina;

$\checkmark$ iniciar o acadêmico em estudos experimentais em animais;

$\checkmark$ divulgar através de publicações em revistas científicas os resultados alcançados através da liga;

$\checkmark$ promoção de cursos, simpósios e congressos com participação de acadêmicos e professores pertencentes à LAU. Fonte: http://www.urousp.honet.usp.br/lau/oqueelau.aspx

\section{A relação com as outras áreas da medicina}

Há relação com todas as áreas do corpo: por vezes ocorrem intervenções acopladas à cirurgia cardíaca (como êmbolos que saem do rim e vão até os vasos cardíacos); transplantes combinados (rim e pâncreas, por exemplo); relações com áreas da radiologia, como o radiodiagnóstico; mapeamento ósseo com a medicina nuclear; radioterapias para pacientes com tumores de próstata; anestesia; cirurgia vascular; intervenções radiológicas, para colocar algum stent em artéria renal (o paciente possui displasia e ocorre a estenose da artéria, fazendo-se necessário dilatála); relações com a ortopedia, em casos de fratura de bacia (ocorre ruptura da bexiga e lesão da uretra, o que leva a quadros de incontinência e impotência).

\section{Preconceitos, mitos e o salto da urologia}

A urologia foi inicialmente confundida com uma especialidade que tratava de doenças venéreas (DSTs). Vivenciei o aparecimento de antibióticos diferentes da penicilina na medicina: tratavam-se dos medicamentos sintéticos como a tetraciclina e a tetramicina.

Depois disso, ocorreu o grande salto da urologia, devido à melhora do instrumental endoscópico, utilizando a tecnologia óptica com luz fria: foi possível, assim, obter luminosidade durante as operações de bexiga, próstata e transplantes renais. A partir disso, cirurgiões vasculares ensinaram urologistas a fazer abordagem de veia e artéria renal. Um dos grandes nomes da história da urologia foi Geraldo Virginelli, grande professor que ensinou a todos os urologistas da época a abordagem de artéria e veia renal.

A urologia foi absorvendo as diversas inovações tecnológicas ligadas à robótica (que se tratam de vias de acesso), como as técnicas percutâneas (surgida em 1985, com o auxílio da radioscopia), utilização de lasers e greenlasers, criocirurgias e radiofreqüências, fatores que permitiram o seu destaque na carreira médica.

Assim, o residente em urologia, que antes era conhecido por suturar ureter à bexiga, se tornou hoje, um profissional capacitado a abordar o retroperitônio, envolvendo estruturas vasculares.

Com avanço com marcadores de doença, houve acréscimo da urologia com a criação do Instituto do Câncer do Estado de São Paulo (ICESP). Um residente opera até 100 prostatectomias radicais em seu estágio, o que é realmente fantástico, em comparação com parâmetros mundiais de formação médica. A urologia no Hospital das Clínicas oferece uma formação para o R5 completa na área de microcirurgia de infertilidade, tratamento de impotência sexual, cirurgia percutânea, cirurgia de câncer de bexiga utilizando tecido intestinal, transplantes de rim etc.

Apesar de todo esse desenvolvimento da robótica e inovações técnicas atreladas, o Complexo Clínicas ainda não possui esse tipo de tecnologia, o que é um absurdo: faz-se necessário enviar os profissionais daqui para o exterior, para aprender a manusear os materiais de $1^{\underline{a}}$ geração.

\section{Mercado de trabalho}

Hoje há cerca de 1350 urologistas no estado de São Paulo: todos querem permanecer na cidade. E como todos sabem, excesso de oferta faz os preços baixarem, ou seja, a tendência é que no estado de São Paulo, o salário médio de um urologista caia.

Para se ter uma idéia, nesse ano, tivemos 
16 candidatos para seis vagas na residência em urologia.

É uma especialidade que cresceu demais, e ainda está crescendo, devido à absorção das últimas invenções da medicina. Assim, é necessária uma revisão para novos membros na especialidade de urologia, seguindo o modelo americano, em que já se calcula um número previsto de urologistas para não ocorrer pletora do mercado de trabalho. Enfim, faz-se necessário abrir novos horizontes. 